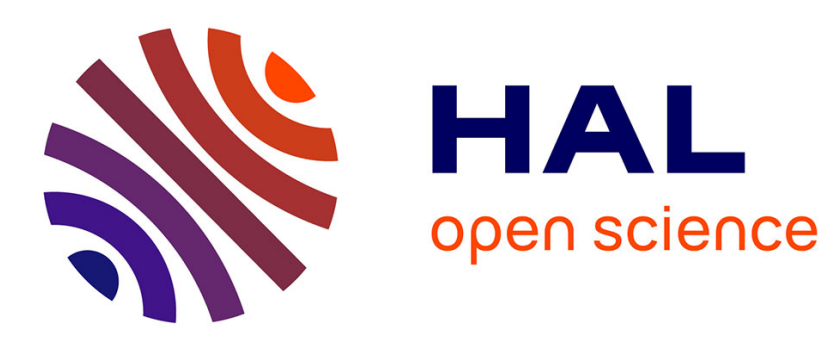

\title{
Organizational routines and cognition: an introduction to empirical an analytical contributions
}

\author{
Nathalie Lazaric
}

\section{To cite this version:}

Nathalie Lazaric. Organizational routines and cognition: an introduction to empirical an analytical contributions. Journal of Institutional Economics, 2011, 7 (2), pp.147-156. 10.1017/S1744137411000130 . hal-00599719

\section{HAL Id: hal-00599719 \\ https://hal.science/hal-00599719}

Submitted on 17 Jun 2011

HAL is a multi-disciplinary open access archive for the deposit and dissemination of scientific research documents, whether they are published or not. The documents may come from teaching and research institutions in France or abroad, or from public or private research centers.
L'archive ouverte pluridisciplinaire HAL, est destinée au dépôt et à la diffusion de documents scientifiques de niveau recherche, publiés ou non, émanant des établissements d'enseignement et de recherche français ou étrangers, des laboratoires publics ou privés. 


\title{
Organizational Routines and Cognition:
}

\section{Introduction to the Special Issue on Routines}

\author{
Nathalie Lazaric \\ University of Nice Sophia Antipolis, CNRS, GREDEG, France \\ Nathalie.Lazaric@gredeg.cnrs.fr
}

\begin{abstract}
:
This article introduces this special issue on routines. It offers some suggestions as to why the concept of routines is considered central in methodological considerations of capabilities and organizational evolution. The contributors to this special issue propose various analytical tools, and provide some missing pieces from the puzzle related to the prominent role of routines. Issues discussed in the papers include methodological individualism. Routines lie between the individual and the firm levels of analysis because they are enacted by individuals in a social context. It is also suggested that a multilevel research agenda provides a finer grained analysis because organizational routines are not isolated units but are entangled among the various organizational layers.
\end{abstract}


In everyday language, a routine is regarded as automatic behavior, in contrast to designed and implemented strategic plans (Cohen, 2006, 2007; Lazaric 2008). Routines are sometimes seen as unconscious acts, while decision-making is deliberate and intentional. This interpretation, which is still shared by some researchers, is unlikely to progress the scientific debate and is out of line with current research on routines. At least since Nelson and Winter (1982), routines are seen as pertaining to organized groups, rather than individuals. Contemporary studies in the cognitive, social and organizational sciences are further refining our use of this concept, involving the notion of procedural memory (Cohen and Bacdayan, 1994), or recurrent interaction patterns (Cohen et al., 1996) and involving change driven by individuals (Feldman, 2000). These complementary views acknowledge the role of individuals and organizations in building new routines.

The concept of routines is at the center of methodological considerations of capabilities and organizational evolution according to Salvato and Rerup (2010) and Rerup and Feldman (2011). These authors suggest unpacking the organizational 'black box' in order to grasp the organizational complexity of the notion of routines. Along these lines, there needs to be an easier connection between the micro and macro levels of this concept. Contributors to this special issue propose various analytical tools, but are in consensus about the need to make progress in this direction. Their diverse insights provide some of the missing pieces in the puzzle and suggest a revised research agenda for observing the prominent role of routines in everyday life. Every 'recurrent interaction pattern' in an organization may be hiding a potential routine. However, not every interaction constitutes a routine, which means that some clarification is required to avoid inaccurate labeling. The definition provided by Pentland (2011) who emphasizes that organizational routines are 'a repetitive recognizable patterns of interdependent actions, carried out by multiple actors '(Feldman and Pentland 2003: 93), is a good starting point. This should not prevent us from continuing the debate since many components of routines are previously-invisible sub-patterns that emerge through the repetition of sequences of actions, but were not designed intentionally by the actors involved. The question should perhaps be why do routines emerge, and in what context, and how are these actions intermingled in the organizational layers that support and enable their creation? The contributors to this special issue 
propose different solutions to these questions. We can investigate these frameworks without any pretensions to classifying the appropriateness or accuracy of the arguments.

Most of the contributors support the idea that routines emerge to coordinate actions into the division of labor within organizations. But is there an 'invisible hand' working to aggregate these various actions? Management and authority appear to be good candidates for the formulation of routines, but were they the only triggers this would mean that organizations were purely bureaucratic processes responding to simplistic feedbacks. The emergence of organizational principles can be interpreted in various ways, some of which we investigate here. We are interested also in 'where to look' to paraphrase Pentland (2011).

\section{Micro-foundations and methodological individualism}

For some authors, methodological individualism is a pre-requisite for understanding the intraorganizational dimension of routines and their motivational components (Abell et al., 2008). Felin and Foss (2011) claim that individuals are a central and crucial piece in the puzzle. That said, methodological individualism is prone to ambiguity and is used in different ways. For instance, it is not always made clear whether it is being proposed that social phenomena should be explained in terms of individuals or social phenomena should be explained by individuals plus relation between individuals (Hodgson, 2007: 97). As Hodgson notes, the second option paves the way for including social structures as an explanatory variable and thus to re-frame the debate. For escaping this dichotomy on methodological individualism versus methodological collectivism, Giddens (1982) and others see agents and structures as inclusive mechanisms, i.e. a source of a permanent creation with enabling and constraining forces.

At first glance, there would seem to be simple disagreement between the proponents of methodological individualism and the defenders of the multilevel perspective. However, the controversy goes deeper, since the authors bring their own epistemological and ontological visions of routines and organizations. This is not new (Lazaric, 2000), but since these discussions have not been 
resolved, they are re-debated from the perspective of the organizational structure and its foundations. For instance, Teppo and Felin (2011) consider these issues from the point of view of individuals. Individualism and other causal mechanisms appear to be critical for understanding organizational management, notably how intentional human action and diverse interactions produce certain strategic phenomena (Abell et al., 2008: 492). Starting from Coleman's (1990) insights, Abell et al. try to build the micro-foundations of management, which they maintain are required to capture firm outcomes and to avoid a too simplistic vision of their micro complexities. Micro-foundations are important because 'the individual level considerations have been consistently black boxed in the received capabilities view' (Abell et al., 2008: 494). In this latter perspective, in order to get a better understanding of the routinization process, the formalization of routines should integrate key insights from the economic theory of the firm as depicted by such authors as Alchian and Demsetz (1972) and Holmström (1982). In sum:

How things are done in organizational settings, both in terms of structure and overall efficiency or creativeness, is a function of who is doing. Even in highly routinized environments, the origins of heterogeneous routines are fundamentally at the individual level. (Felin and Foss: 2005: 450).

For this reason, 'collective structures are dependent on the individuals who make up the organization' (ibid: 450). Felin and Foss (2011) go a step further, claiming that the behavioral roots of this debate impede organizations from fully integrating feedbacks in a manner suitable to deal with novelties. According to them the 'poverty of stimulus' makes organizations more receptive to past experience than to becoming inventors of new inputs supported by individuals. In this debate, Hodgson and Knudsen (2011) while endorsing the role of human agency, argue that the term 'methodological individualism' is misleading. Opposing individuals to social structures creates a false dichotomy. Indeed human capacities remain caused and its source of change has multiple ranges of explanation going beyond the solely individual arena. 
Some misunderstandings about the notion of routines emerge from readings of Nelson and Winter's (1982) book. They do not define this concept as behavioral "lock in" or the product of past behavior, but as a source of knowledge that needs constant renewal and new understanding in order to make sense within the firm and to achieve appropriate coordination. As Winter (2011) explains in his contribution here, the reformulation of this notion based on the heritage of Michael Polanyi transforms the 'state of the art' through the integration of two important concepts: 'personal knowledge' and 'tacit knowledge" . This integration represents a departure from the traditional Simonian vision of routines as programs, an idea diffused by the Carnegie School (see Feldman, 2000 for a discussion). Also, the notion of 'personal knowledge' implicitly transforms the traditional vision of organizations by emphasizing the difficulties involved in articulating and transferring knowledge inside firms and enabling the emergence of organizational knowledge not based on initially individual skills.

Nelson and Winter for many years worked with the Rand Corporation, which oversaw several military and civilian technological programs, and they worked closely also with the Carnegie School. Based on this experience Nelson and Winter became thoroughly familiar with the radical technical uncertainty characterizing innovation. Publication of March and Simon's (1963) Organizations had a decisive impact on the whole scientific community (Nelson, 2006). Nelson and Winter were influenced by this book; this led to their consideration of dysfunction in major military organizations and the role of institutions in launching technological innovations. They saw the firm as bearing the mark of these large structures whose decisions, far from responding to market signals, relied on specific rules. Their original Schumpeterian vision of the firm was modulated by their observation of these dysfunctions. Instead of the idea of routines evoked by Schumpeter, or Simon's concept of a program, Nelson and Winter reformulated the notion. Their definition of routines is based on several essential questions related to where individual skills and organizational knowledge reside, as the basis for a successful production process.

The capacity for firms to survive depends on the transformations that are put in place promoted either by the permanent reconfiguration of routines or their new combination. Some transformations are motivated by the individual and organizational knowledge present in the firm. The literature tends to 
focus not on these sources of change but on the changes promoted by exogenous shocks. This dynamics is based on Schumpeterian thinking in which firms are continuously motivated to innovate in order to survive in a non-stationary environment, and where innovation itself promotes further transformations. This implies a double transformation motivated by internal and external forces, whose real origins are sometimes difficult to identify (Winter, 2006). In this context, the notion of organizational routines, a pillar of the evolutionary edifice, is a source of both stability and change in the organization. The idea of change is a difficult one, and many talk of routines and innovation as oppositional. However, this hides the underlying organizational reality. Routines evolve according to various internal or external pressures and create focal points around which organization members agree to organize their work or activities. The outside observer might see only the external forces pushing for a modification of routines, but not the internal 'governance' pushing for their transformation. There is a view that changes to routines are more likely to be determined by changes in the environment (Cohen et al., 1996: 683; Andersen, 1994). However, Schumpeterian theory reveals two sources of renewal. First, the 'combinatorics of routines', which occurs through a combination of sub-elements. Although relevant, this approach is undeveloped (Becker, Knudsen and March, 2006: 362). Second, the unreliable process of replication of internal elements. Indeed, the firm's ability to copy and/or to extend routines is a source of competitive advantage. This mechanism may be imperfect and costly, but can also be a valuable source of evolution and change. Winter (1996) develops this in trying to explain the extension and renewal of knowledge bases in a given competitive environment (Becker and Lazaric, 2003). Based on the reasons put forward above, Winter (2011) explains in his contribution the objections to imputing Skinner-type 'behaviorist' arguments to his previous work with Nelson.

\section{Organizations and motivational feedbacks}

In their essay Felin and Foss (2011) underline the excessive emphasis placed on experience and repetition as the organizational antecedents to routines and capabilities. According to them, lessons learned by the organizations are 'black boxed', impeding the integration of endogenous sources of 
novelty. The 'poverty of stimulus' illustrates this process where internal elements interfering with recurrent internal patterns of interactions are not fully understood. This is a 'chicken and egg' type problem in the sense that whether and to what extent we are able to differentiate the initial cause from the final cause of this organizational process. To escape this circularity, we need to identify the emergence of the organizational principles, their origin, legitimacy and potential efficiency. In this direction, Rerup and Salvato (2010), advocate for multilevel research on routines and capabilities. They suggest that routines should be broken down into sequences of individual actions to understand their evolution and effectiveness while 'breaking organization-level routines across hierarchical levels to understand the role of different individual rationalities in routines performance` (Rerup and Salvato, ibid: 14). Observation of individuals in organizations performing different activities and encompassing different understandings of routine would seem appropriate. In this context, the problem of the 'poverty of stimulus' can be transformed in feedback opacity inside and outside the organization. Individuals have various goals and various motivations which may be in accordance or conflict with the organization's goals. Organizational layers create opacity between individual behavior and organizational principles.

For Greve (2008), this opacity stems from the fact that feedbacks in organizations are not automatic, and within organizations, multilevel organizational goals tend to make feedback more difficult because:

the organization level sets the goal variables for lower levels ( ...) but does not directly influence lower level -routine modification. First often the individual behavior is part of multi person routines ( ...) as the result the person and the decision are not tightly associated. Second the goal is often assigned higher level the specific routines (...)[Consequently] the goal and the routine are not tightly associated. In such cases, is often not clear whether the individual will feel responsible for making any specific change, and that change will be a modification of a routines (Greve, 2008: 199).

In contexts where the feedbacks between hierarchy and individuals are confused, motivational issues may be a way of reducing this gap. Witt (2011) claims that we should look more closely at various sources of motivation, i.e. intrinsic and extrinsic ones. Indeed, the expression of individual knowledge 
inside organizations presupposes sufficient mutual fits in cognitive frames (proposition 2). If individuals are sharing the same cognitive framework, identification with organizational goals will be easier. Thus, shared cognitive frameworks need to be established among individuals based on common knowledge and common goals. This may allow organizations to identify common values reducing the cognitive distance between individuals and instilling some coordinating principles. For Witt (2011, proposition 4) the sharing of cognitive frameworks and social values enables the identification of intrinsic motivations and the building of patterns of recurrent interactions. The self determination theory describes motivation as an autonomous variable which may sustain some degree of regulation and control (Deci and Ryan, 1985; Deci et al., 1999). Starting from this premise, intrinsic motivation refers to performance of an activity because it is interesting and provides rewards in terms of the basic psychological need for autonomy, competence and relatedness. This source of motivation involves a conscious act and the commitment of individuals to take part in a new learning process. Extrinsic motivation, on the other hand, refers to the performance of an activity because of its instrumental or separable external outcomes, e.g. monetary reward (Deci, 2008).

For Postrel and Rumelt (1992), going beyond individual impulsiveness and executing new routines requires new values and learning of new habits. Consequently, incentive systems on their own are not sufficient to change routines because they often conflict with employees' intrinsic motivations (fear of instrumentalism and loss of autonomy). As Leibenstein $(1987,1979)$ explains, authority and hierarchy cannot substitute for this deliberate effort and cannot control the daily routines of members because they are able to exercise discretionary power. This means that the origin of the effort and, more specifically, the conditions under which individuals can reconcile their personal interests with those of the organization, become critical. Building intrinsic motivation is difficult because 'individual and organizational rationality are engineered "outcomes", not natural endowments“ (Postrel and Rumelt, 1992:432). However, a closer look at this issue might help to clarify some of the discrepancy observed between 'ostensive' and 'performative' routines, and illustrate the difficulties of trying to control routines in the face of individuals' free will (Feldman and Pentland, 2003). 
As Feldman (2000) suggests, routines are 'emergent accomplishments' that need to be made sense of in order to be deployed by workers in the right way (i.e. requiring minimal supervision of their application). Social mechanisms are required to support the organization's values and social goals. In this perspective, an 'individualist" view of routines may provide a better understanding of the social underpinnings that become taken for granted when routines are activated (see also Lazaric and Raybaut, 2005; Zbaracki and Bergen, 2010; Witt, 2011).

\section{Routines as multilevel mechanisms}

Organizational routines, rather than being isolated units may appear to be intertwined with various feedbacks (Rerup and Salvato, 2010). The emergence of mechanisms of change stemming from individuals, but which have an impact on the organization ('upward causation'), and the changes within organizations that radically affect individuals ('reconstitutive downward causation ") (Hodgson, 2007:108) are worthy of investigation. Routines clearly lie between the individual and firm levels of analysis because they are enacted by individuals, but within a social context. In his contribution Vromen (2011) claims that we should conceive routines as multilevel mechanisms, i.e. patterns of behaviors that generate firm behaviors. This proposal helps to broaden our view of routines by encompassing others' interaction mechanisms and by decomposing emergent outcomes and the links within and among them. More precisely ' it helps in getting a clearer picture of how skills and routines are ontologically (rather than metaphorically) related to each other'. Vromen does not claim that his standpoint solves all the problems, but that it can be seen as a counter proposal to avoid a takeover by reductionist arguments. Pentland (2011) extends the debate and invites us to consider the granularity of the routines for appreciating their 'practical consequences'. For him, the intersection between action and experience matters especially in the context of ecologies of routines that emerge in networks such as the 'purchase-to-pay cycle'. He encourages a focus on real routines in order to avoid confusion generated 'by disconnecting words from their meaning in practice'. Based on the empirical evidence, former deliberating about foundations should be directed to the tools and methods required to analyze them (a similar judgment is found in Becker et al., 2005). 


\section{Technological artefacts as mediators of activities}

A valuable contribution to this debate in describing how organizational routines co-evolve with various technological artefacts and more precisely about how 'artefacts and materiality [are brought] to the center of the routines and the Routines Theory', is discussed by D'Adderio (2011) in her contribution. From this perspective, technological artefacts are sources of new forms of procedural memory, but also generate potential rigidity (D'Adderio, 2003, 2008). Artefacts then are 'mediators of human cognition and activity', and are at the interface between ostensive visions of routines and their performance. As a result, they capture, encode and select among performances while having an impact on performative routines -and vice versa (D'Adderio, 2011).

This finer grained analysis provides a means of grounding and situating routines and empirical research. Pentland recommends some other guidelines to enable a better understanding of the link between 'stability and change in routines', the links between 'routines and capabilities' and the need to investigate more fully the 'ecologies of routines' (for complementary discussions see Pentland and Feldman, 2008 ; Becker and Lazaric, 2009). To sum up and to paraphrase Pentland, in this debate, we should always be connected to our object of observation. Routines are often considered to be mundane, ordinary 'objects' performed in daily life. Thus, in exploring them as 'scientific objects ' we may be tempted increase their complexity as our analytical representations hide our normative vision of what organizations are (or what they should be) in some specific context. I invite readers of this special issue to join in this discussion in their future research. 


\section{References}

Abell, P., T. Felin, T. and N.J. Foss (2008), 'Building micro foundations for the routines, capabilities, and performance links', Managerial and Decision Economics, 29: 489-502.

Alchian, A. and H. Demsetz (1972), 'Production, information costs, and economic organization', American Economic Review, 62 (December): 777-795.

Anderson, E.S. (1994), Evolutionary economics: Post-Schumpeterian contributions, Pinter, London.

Becker, M. and N. Lazaric (2003),'The influence of Knowledge in the replication of routines', Economie Appliquée, 16, (3): 65-95.

Becker,M., N. Lazaric, R.R. Nelson, and S.G Winter (2005), 'Applying routines in analysing organizations', Industrial and Corporate Change, 14 (5): 775-791.

Becker, M., T. Knudsen and J.G. and March (2006), 'Schumpeter, Winter, and the sources of novelty', Industrial and. Corporate. Change, April 1, 15(2): 353- 371.

Becker, M. and N. Lazaric (eds). (2009), Organizational routines: Advancing empirical Research, Edward Elgar, Cheltenham UK.

Clark, P. (1999), Organisations in Action: Competition between Contexts, Routledge, London.

Cohen, M.D. and P. Bacdayan (1994), 'Organizational Routines are Stored as Procedural Memory: Evidence from a Laboratory Study’, Organization Science, 5 (4): 554-68.

Cohen, M. D., R. Burkhart, G. Dosi, M. Egidi, L. Marengo, M. Warglien, and S. G.Winter (1996), 'Routines and Other Recurring Action Patterns of Organizations: Contemporary Research Issues', Industrial and Corporate Change,5(3) : 653-697.

Cohen, M. D. (2006), 'What's different is routine', Industrial and Corporate Change, 15(2): 387-390.

Cohen, M. D. (2007), 'Reading Dewey: Reflections on the Study of Routine', Organization Studies. 28, (5): 773-786.

Coleman, J. (1990), Foundations of Social Theory, Harvard University, Cambridge University Press.

Cyert, R. and J.G. March (1963), Behavioral Theory of the Firm, Oxford: Blackwell

D'Adderio, L. (2003), 'Configuring Software, Reconfiguring Memories: the Influence of Integrated Systems on the Reproduction of Knowledge and Routines', Industrial and Corporate Change, 12, (2): 321-350.

D'Adderio, L. (2008), 'The performativity of routines: Theorising the influence of artefacts and distributed agencies on routines dynamics', Research Policy, 37(5): 769-789.

D’Adderio, L. (2011), 'Artefacts at the centre of routines: performing the material turn in routines theory', Journal of Institutional Economics, 7(2), June. doi:10.1017/S174413741000024X .

Deci, E. L. and R. M. Ryan (1985), Intrinsic motivation and self-determination in human behavior. New York: Plenum.

Deci, E., R. Koestner, and R.M. Ryan (1999), 'A meta analytic review of experiments examining the effects of extrinsic rewards on intrinsic motivation', Psychological Bulletin, 125 ( 6): 627-668.

Deci, E. (2008), 'A self determination theory view of Rewards, Motivation and Organizations', Inaugural Speech presented at the INAPOR conference, 15-16 February Paris.

Feldman, M. S. (2000), 'Organizational Routines as a Source of Continuous Change', Organization Science. 11 (6): 611-629.

Feldman, M. and B. T. Pentland, (2003), 'Reconceptualizing Organizational Routines as a Source of Flexibility and Change', Administrative Science Quarterly. 48(1): 94-118. 
Felin, T. and N.J. Foss, (2005), 'Strategic organization: A field in search of micro-foundations', Strategic Organization, 3: 441- 455 .

Felin, T. and N. J. Foss (2011), 'The Endogenous Origins of Experience, Routines and Organizational Capabilities: The Poverty of Stimulus', Journal of Institutional Economics, 7(2), doi:10.1017/S1744137410000214

Greve, H.R. (2008), 'Organizational routines and performance feedback', In: (ed) Becker M, Handbook of Organizational routines, Edward Elgar, Cheltenham London: 187-205.

Hodgson, G. M. (2007), 'Institutions and Individuals: Interaction and Evolution', Organization Studies, 28 (1):95-116.

Hodgson G.M. and T. Knudsen ( 2011), Poverty of stimulus and absence of cause: Some question for Felin and Foss, Journal of Institutional Economics, 7(2), doi:

Holmström, B. (1982), 'Moral Hazard in Teams', Bell Journal of Economics, 13: 324-40.

Lazaric, N. (2000), 'The role of routines, rules and habits in collective learning: some epistemological and ontological considerations', European Journal of Economic and Social Systems, 14, (2): 157- 172.

Lazaric, N. (2008), 'Routines and routinization: an exploration of some micro-cognitive foundations', In: (ed) Becker M, Handbook of Organizational routines, Edward Elgar, Cheltenham London: 205-227.

Lazaric, N. and A. Raybaut, (2005), 'Knowledge, hierarchy and the selection of routines: an interpretative model with group interactions', Journal of Evolutionary Economic, 15 (4): 393-421.

Leibenstein, H. (1979), 'A branch of economics is missing: micro-micro theory', Journal of Economic Literature, 17: 477-502.

Leibenstein, H. (1987), Inside the Firm: the Inefficiencies of Hierarchy, Cambridge, Harvard University Press.

Nelson, R., and S. Winter (1982), An Evolutionary Theory of Economic Change, Cambridge Mass., Belknap Press of Harvard University Press.

Nelson, R. R. (2006), 'Commentary on Sidney Winter's "Toward a neo-Schumpeterian theory of the firm', Industrial and Corporate Change, 15(1): 145-149.

Pentland, B. (2011), 'The foundation is solid, if you know where to look: Comment on Felin and Foss', Journal of Institutional Economics, 7(2), doi:10.1017/S174413741000041X.

Pentland, B. and M.S. Feldman (2008), 'Issues in empirical field of Organizational routines', in M. Becker (ed) , Handbook of Organizational routines, Edward Elgar, Cheltenham London: 281-301.

Postrel, S., and R. P. Rumelt (1992), 'Incentives, Routines, and Self-Command', Industrial and Corporate Change, 1, (3): 397-425.

Rerup, C. and M.S. Feldman (2011), 'Routines as a source of change in organizational schema: The role of trialand-error learning', Academy of Management Journal, Forthcoming.

Salvato, C. and C. Rerup (2010), 'Beyond collective entities: Multilevel research on organizational routines and capabilities', Journal of Management, doi:10.1177/0149206310371691.

Vromen, J. (2011), 'Routines as multilevel mechanisms', Journal of Institutional Economics, 7(2), doi:10.1017/S1744137410000160

Winter, S. G. (2006), 'Toward a neo-Schumpeterian theory of the firm', Industrial and Corporate Change, Oxford University Press, 15(1) :125-141.

Winter, S. G. (2011), 'Problems at the Foundation? Comments on Felin and Foss', Journal of Institutional Economics, 7(2), doi: . 
Witt, U. (2011), 'Emergence and functionality of organizational routines: An individualistic approach', Journal of Institutional Economics, 7(2), doi:10.1017/S1744137410000226.

Zbaracki, M.J., and M. Bergen (2010), 'When Truces Collapse: A longitudinal study of price adjustment routines', Organization Science, 21(5): 955-972. 